\title{
THE APPLICATION OF CHELATE COMPOUNDS IN ANALYTICAL CHEMISTRY
}

\author{
R. BELCHER \\ Department of Analytical Chemistry. University of Birmingham. \\ P.O. Box 363, Edgbaston. Birmingham B15 2TT, England
}

\begin{abstract}
The application of chelate reactions in a general way began a few years before the turn of the century, but the term 'chelate' was coined considerably later by Morgan and his colleagues at the University of Birmingham, who made the first systematic studies. Work in this field has continued at Birmingham for over half a century, apart from a break during the war years. During the last twenty-five years the main attention has been confined to the analytical applications. Several new reagents have been discovered and have been applied in spectrophotometry, spectrofluorimetry, titrimetry, gravimetry, gas-liquid chromatography and mass spectrometry. A number of new synthetic processes has been developed and various structural studies have been made.
\end{abstract}

\section{INTRODUCTION}

Chelate compounds were known in the last century, but were first given this name by Morgan and Drew ${ }^{1}$, working in the University of Birmingham, just over half a century ago. The term is derived from the Greek, chele, meaning a crab's claw and originally was used to describe the ring itself. Later, it was used to describe the complete structure. Morgan and his colleagues made the first truly systematic studies of this class of compound, but they were mainly interested in the $\beta$-diketones. Recently, we had occasion to analyse some of the original specimens and found their purity unimpaired after more than 50 years. Some time ago, I discovered that my office, used to be the laboratory of Sir Gilbert Morgan, but was converted in 1926 . Hence, I can claim that the compounds, which were first termed chelate compounds, were initially prepared in my office!

The first known application of a chelating reaction in chemical analysis was described by Pliny in the first century A.D. ${ }^{2}$. Ferrous sulphate, used as an adulterant in copper sulphate, was identified by the blue-black stain it produced on papyrus soaked in an extract of gall nuts. The first application of a synthetic chelating reagent was due to Ilinski and von $\mathrm{Knorre}^{3}$ in 1885, who used 1-nitroso-2-naphthol for the selective precipitation of cobalt. Other reagents were soon to follow. Some compounds were known long before their possibilities as reagents in chemical analysis were realized. The more important early organic reagents and the dates of their introduction in analysis are listed in Table 1. 


\section{R. BELCHER}

Table 1 . Some early organic chelating reagents and the dates of their first application

\begin{tabular}{|c|c|c|c|}
\hline Reagent & Year & Author & Application \\
\hline 1-Nitroso-2-naphthol & 1885 & Ilinski and von Knorre & Co \\
\hline 1,5-Diphenylcarbohydrazide & 1900 & Cazeneuve & Several metals \\
\hline Acetylacetone & 1904 & Pulsifer & $\mathrm{Fe}$ \\
\hline Dimethylglyoxime & 1905 & Tschugaeff & $\mathrm{Ni}$ \\
\hline Salicyclic acid* & 1907 & Gregory & $\mathrm{Fe}$ \\
\hline Cupferron & 1909 & Baudisch & Several metals \\
\hline Alizarin & 1915 & Atack & $\mathrm{Al}$ \\
\hline$\alpha$-Benzoin-oxime & 1923 & Feigl & $\mathrm{Cu}$ \\
\hline Dithizone & 1925 & Fischer & Several metals \\
\hline 8-Quinolinol & 1926 & Berg and Hahn (independently) & Several metals \\
\hline Rhodizonic acid & 1926 & Feigl & Several metals \\
\hline $\begin{array}{l}p \text {-Dimethylaminobenzal- } \\
\text { rhodanine }\end{array}$ & & & \\
\hline $\begin{array}{c}\text { rhodanine } \\
22^{\prime} \text {-Dipyridyl }\end{array}$ & 1928 & Feigl & $\mathrm{Ag}$ \\
\hline 2,2'-Dipyridyl & 1930 & Hill & $\mathrm{Fe}$ \\
\hline Tris(phenanthroline)Fe ${ }^{I I}$ & 1931 & Walden, Hammett and Chapman & Redox indicator \\
\hline
\end{tabular}

* It is emphasized that the dates refer to the first application in chemical analysis, even though the compound may have been known or its reactions noted earlier. Salicyclic acid provides some difficulties: according to Welcher ${ }^{4}$ the reaction with iron was noted by Vogel in 1876: several later investigators commented on it before the turn of the century, but it was first used for analysis by (iregory (Welcher, loc cit): hence this is the reference quoted above. Yet Pulsifer (1904) (supra) used the reaction to compare it with acetylacetone, but gives no reference to earlier work; he may have been the first to use it. Only an extensive examination of the original papers could establish the exact situation. It might well turn out that salicylic acid was the first synthetic organic reagent to be used in chemical analysis.

Morgan's studies on chelate compounds continued at Birmingham University until 1925, when he was succeeded as Mason Professor by Haworth. Studies in this field were continued by Drew, Cox, Wardlaw, Pinkard ${ }^{5}$ and their co-workers, but with a change in direction; the now classical structural studies were begun. These studies continued almost to the period of the 2nd World War, but then languished for several reasons. A decade was to elapse before work in this field was to be resumed, and then with an entirely different objective.

In 1948, the foundations of the School of Analytical Chemistry were laid down, and work on chelate compounds has continued in one form or another from that time to the present day. New analytical reagents have been developed, but, in addition, many contributions to structural and synthetic chemistry have been made. This lecture provides me with an opportunity to present, for the first time, a coordinated picture of the Birmingham contribution.

\section{FLUORINE-SUBSTITUTED REAGENTS}

One of our earlier investigations in analytical chemistry was concerned with the effect of fluorine substitution on well-established reagents. In more recent times, we have used fluorine-substituted reagents with great success; at that time, no outstanding new reagent was found, but some unusually interesting effects were observed. Various fluoro- and trifluoromethylsubstituted mandelic acids ${ }^{6}$, iminazoles ${ }^{7}$, dimethylglyoximes ${ }^{8}$ and 8 -hydroxyquinolines ${ }^{9,10}$ were prepared. 


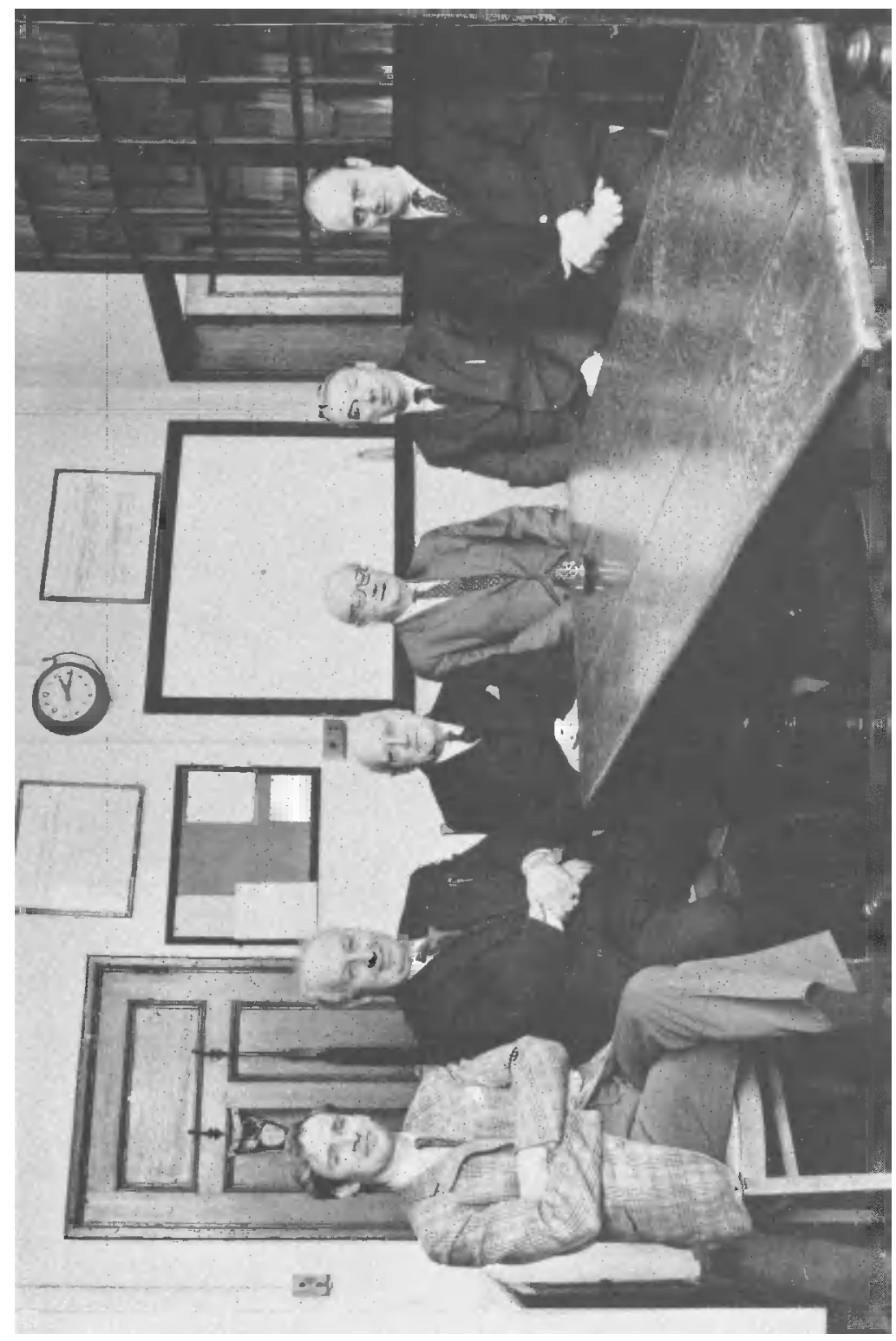

造它总

触

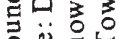

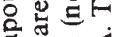

要品

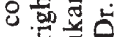

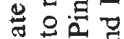

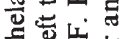

둥

造证

要出问

龸吉

急驾

矛递

䀡它

ติ

艊

to

$\Sigma$ 芩

동잉

氜它志

造

哕总吉

的完之

을

중

홍

要运

후응

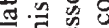

OF

덩혀는

$\sim N$.

象

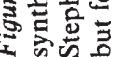




\section{R. BELCHER}

It was found that the trifluoromethyl group had a surprisingly large effect on the basicities of the heterocyclic nitrogen functions which are lowered considerably. This was noticeable both with the substituted iminazoles and 8-hydroxyquinolines. The reactions of the 5-and 6-trifluoromethyl derivatives were very similar to the corresponding 5- and 6-methyl derivatives. Surprisingly, 7-trifluoromethyl-8-hydroxyquinoline gave no precipitates with any of the many ions tested; as is well known, 8-hydroxyquinoline derivatives usually give precipitates with most ions. A further abnormality is that its melting-point is $150^{\circ} \mathrm{C}$ higher than those of the other isomers; in similar $o$-derivatives the melting-points are of the same order. These effects probably arise from unusually strong intramolecular hydrogen bonding between the hydroxyl and trifluoromethyl groups.

Particularly interesting results were obtained with 1,1,1-trifluorobutan2,3-dione dioxime (Figure 2), which was synthesized for the first time. It is

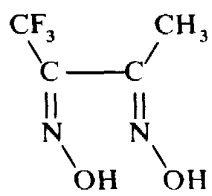

Figure 2. 1,1,1-Trifluorobutan-2,3-dione dioxime

well known that three isomeric 1,2-dioximes can theoretically exist, but all three isomers have only been isolated in the aromatic series. In the aliphatic series, only the anti isomer, which gives a $2: 1$ oxime :nickel complex, had previously been isolated. The crystalline dioxime which was isolated was the amphi form; it yielded with nickel ions the 1:1 complex and was drab green in colour. The mother liquor contained some of the anti isomer, for a 2:1 red complex was obtained when nickel ions were added. It was not possible to recover the parent dioxime from the nickel for when the latter was heated with various reagents it reverted to the amphi form. This is the first and, as far as I know, the only time the amphi isomer has been isolated in the aliphatic series.

Because of the asymmetry of this molecule, two amphi forms are possible, but only one is obtained. Probably the reason for the remarkable stability of this amphi isomer is the exceptionally acidic $\mathrm{OH}$, leading to a strong intramolecular hydrogen bond; moreover, the amphi isomer in which $\mathrm{CF}_{3}$ is trans to $=\mathrm{N}-\mathrm{OH}$ ought to be less sterically strained than any of the other three possible forms ${ }^{11}$.

\section{DIOXIME REAGENTS}

Later work on dioximes was confined to the introduction of pyridine groups in place of the methyl groups in dimethylglyoxime. Thus, $2,2^{2}$-pyridildioxime (the 2-pyridine analogue of benzildioxime) was prepared, and all three possible isomers were isolated. The orientation of the pyridine nitrogen atom had an important bearing on the stabilization of the individual isomers 
of the dioxime, as well as providing an additional chelation centre for reactions with metal ions ${ }^{12}$.

Synthesized 2,3'- and 2,4'-pyridildioximes were shown to contain three isomers each, although theoretically these asymmetric dioximes should exist in four forms (two amphi isomers). The 3,3'-, 3,4'- and 4,4'-pyridildioximes could not be resolved, and it was concluded from reactions with nickel that only one isomeric species, the anti form, exists for three compounds. A further point of interest is that when the degree of asymmetry of the molecule is increased, as in the dioximes containing one phenyl and one pyridyl radical, the theoretically possible four isomers were isolated for the first time and cis-trans isomerism in the anti-nickel complex was observed.

\section{EDTA INDICATORS AND SOME EDTA ANALOGUES}

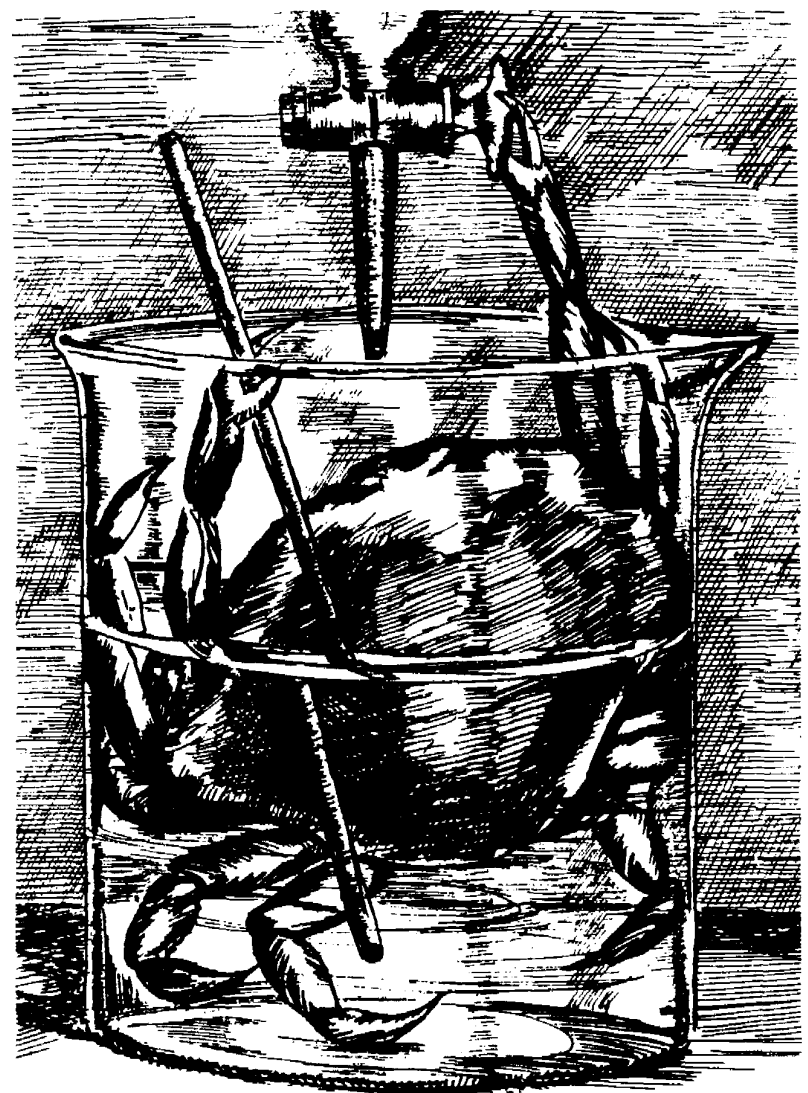

A pen illustration by J.E.Williams

Does this titration involve a chelate?

Figure 3. 


\section{R. BELCHER}

By the early 1950s, the use of EDTA as a titrant had become widespread and many new applications were constantly being found. Only a few indicators were known and there was a need for better ones. An examination was made of certain hydroxyazo dyestuffs which had suitable structures, and several useful new indicators were found ${ }^{13}{ }^{14}$; for example, Acid Alizarin Black $\mathrm{SN}^{15}$ for calcium, and Fast Sulphon Black for copper ${ }^{16}$. Several new polyaminopolycarboxylic acids ${ }^{17}, 18$ were synthesized and their stability constants determined. Martell and Calvin had predicted on theoretical grounds that if 1,2-diaminocyclopentane- $N, N, N^{\prime}, N^{\prime}$-tetraacetic acid (CPDTA) could be synthesized, it would be an even more powerful complexing agent than the corresponding cyclohexane derivative (CDTA). Accordingly we synthesized this compound, together with others of the series (the cycloheptane (CHDTA) and the 1,3- and 1,4-diaminocyclohexane derivatives), but contrary to the prediction, CPDTA turned out to be a weaker complexing agent than CDTA, indicating that there are other factors more important than entropy considerations. CHDTA is a stronger complexing agent than CDTA, but as would be expected, the other compounds are weaker.

When an attempt was made to synthesize 2,3-butanediamine- $N, N, N^{\prime}, N^{\prime}-$ tetraacetic acid (BDTA), both the $d l$ and meso forms were isolated and there was a great difference in complexing power. This was the first time that optical isomers had been isolated in this series ${ }^{19}$.

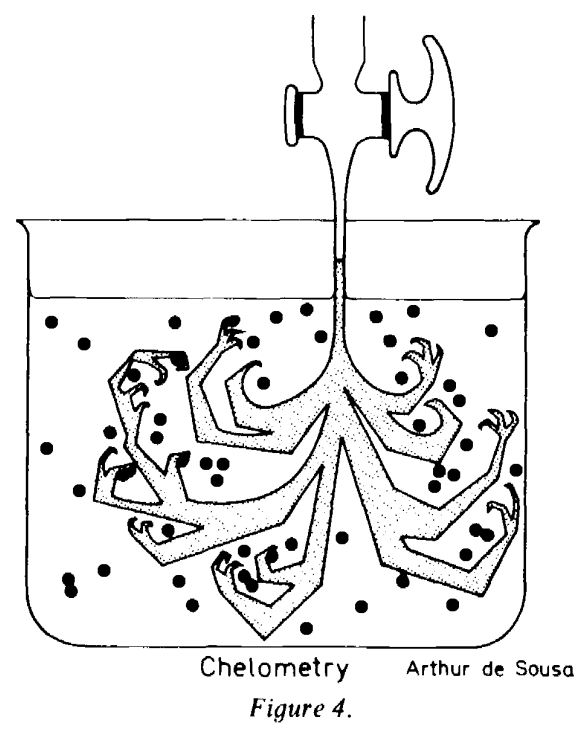

Amongst the new indicators which were synthesized was Alizarin Fluorine Blue $^{20}$, as indicator for certain heavy metals, especially molybdenum(vi) (and which later was found to provide the first direct colour reaction with the fluoride ion $^{21}$ ). The structure shown in Figure 5 has been proposed 


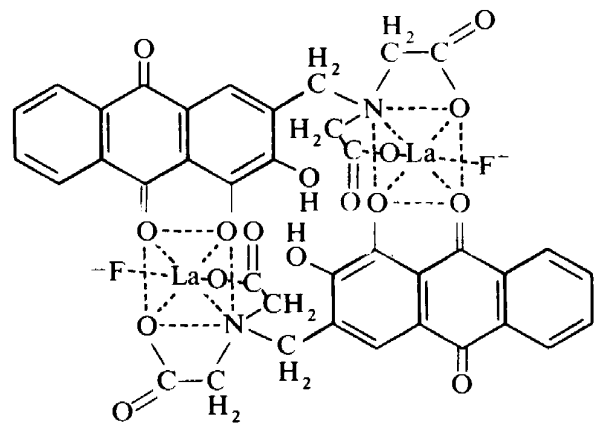

Figure 5. Structure of the lanthanum complex of Alizarin Fluorine Blue according to Langmyhr, Klausen and Nouri-Nekou ${ }^{21}$

recently ${ }^{21 a}$. Certain fluorescent chelating indicators were prepared, e.g. $o$-dianisidine- $N, N, N^{\prime}, N^{\prime}$-tetraacetic acid, benzidine-3,3'-dicarboxylic acid$N, N, N^{\prime}, N^{\prime}$-tetraacetic acid and 3,3'-dihydroxybenzidine- $N, N, N^{\prime}, N^{\prime}$-tetraacetic acid ${ }^{22-24}$. Various heavy metals can be titrated with great accuracy when these indicators are used. The first compound is generally considered to be one of the best indicators available for the titration of copper. Many fluorescent derivatives of 7-hydroxycoumarins have also been synthesized and their structures as well as their reactions have been investigated ${ }^{25,26}$

The reagent variously known as Calcion IREA or Calcichrome was first recommended as a selective spectrophotometric reagent for calcium by Lukin and his co-workers ${ }^{27}$, who suggested a bis-azo structure. Some two or three years later, other investigators ${ }^{28}$ used the reagent as an EDTA indicator, but suggested that it had a tris-azo structure. Unfortunately, they used a different trivial name and this later led to some confusion; as the reagent was sold under the different names, they were thought to be different compounds.

None of these investigators had produced any convincing evidence for either structure; hence a more detailed examination was made by MendesBezerra and Stephen ${ }^{29}$, whose findings supported completely the original bis-azo structure of Lukin. Extensive degradation studies would be necessary to establish the complete structure of such a comparatively large molecule, but the work proved beyond doubt that the commercial specimens were the same compound. This indicates once again the danger of the use of different trivial names; with substances so difficult to purify it would not be the first time that the one had naïvely been stated to be better than the other.

\section{FERROIN AND CUPROIN TYPE REAGENTS}

Amongst the most important organic reagents are those giving 'ferroin' and 'cuproin' type compounds. From a theoretical standpoint, they are also amongst the most interesting. These compounds are not too easy to synthesize and new, more easily synthesized compounds have been prepared, containing the same analytico-functional chromophores, for reactions with 
<smiles>[R]c1cccc(-c2nc(-c3cccc([R])n3)c(-c3cccc([R])n3)nc2-c2cccc([R])n2)n1</smiles><smiles>[R]c1cccc(-c2nccnc2-c2cccc([R])n2)n1</smiles>

(III), $\mathbf{R}=\mathbf{H} \quad \mathbf{R}$ (IV). $\mathrm{R}=\mathrm{CH}_{3}$

(V), $\mathrm{R}=\mathrm{H}$

(VI). $\mathrm{R}=\mathrm{CH}_{3}$<smiles>[R]c1cccc(-c2nc3ccccc3nc2-c2cccc([R])n2)n1</smiles>

(VIII. R - H. or $\mathrm{CH}_{3}$<smiles>Cc1ccc2ccc3ccc(C)nc3c2n1</smiles>

(VIII)<smiles>[R][R](=C)c1cccc(C2=NCCN=C2c2cccc([R])n2)n1</smiles>

Figure 6. Some pyridyl-substituted pyrazines and their relationship to 2,9 dimethyl-1,10phenanthroline(VIII) and terpyridine(IX)

$\mathrm{Cu}^{\mathrm{I}}$ and $\mathrm{Fe}^{\mathrm{II}}$. Thus, a series of quinoxalines of which 2,3-bis(2-pyridyl)quinoxaline is the parent, has shown how new, analytically useful reagents can be developed ${ }^{30}$. Similar considerations of pyridyl-substituted pyrazines (Figure 6) have extended the range of highly sensitive ferroin-type reagents and have increased the understanding of the stereochemical effects which lead to selectivity in the reactions of particular compounds with copper(I $)^{31}$.

\section{RHODANINES}

Rhodanine and its analogues are well-known reagents for silver, but there were some puzzling features about this type of reagent. There were doubts about the structure of the complex, for it was not certain where coordination took place; if the imino-hydrogen is replaced, the obvious 


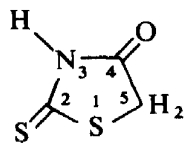

Figure 7. Substitution in the rhodanine nucleus

coordination would be on to the 2-position, but this would give an unstable ring structure. Furthermore, some reagents have been prepared in which the imino-hydrogen is substituted, yet these are still sensitive reagents for silver. It was not known where silver substituted in such reagents.

The effects of substituent changes at each position of the rhodanine ring on the silver binding properties of the reagent were studied. As a result of this work it was shown that when the imino-hydrogen was substituted, an entirely different type of reaction occurred. With rhodanines containing the unsubstituted imino-hydrogen, the silver complex had a polymeric structure (Figure 8). This accounted for the 1:1 constitution of silver rhodanine, yet

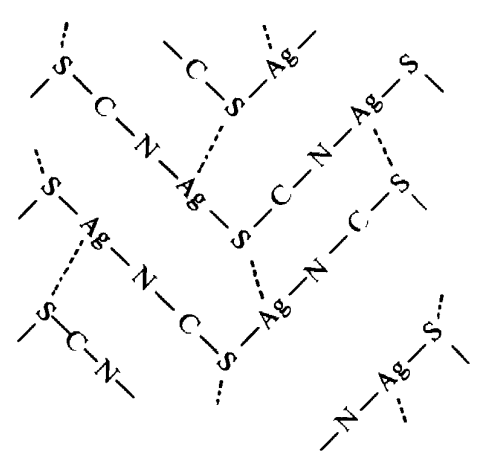

Figure 8. Structure of the silver rhodanine complex

allows coordination on to the sulphur atom of another molecule. This polymeric structure also explains why it is not possible to achieve any great degree of solubility for the silver complexes formed by rhodanine-type reagents.

It was shown that the functional group for silver, found in rhodanine-type reactions, can be found in many other reagents which react with silver, but which do not have the rhodanine structure. (See Figure 9).

Many new rhodanine derivatives were synthesized in an attempt to improve on Feigl's classical p-dimethylaminobenzal rhodanine reagent. Of great interest were the $N$-substituted pyridine derivatives, which gave particularly sensitive reactions with mercury and palladium. The mechanism of the chelation reaction, which differed from that of the unsubstituted rhodanines, was not established ${ }^{33}$. 


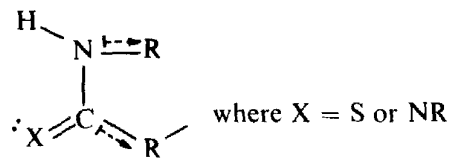

Figure 9. The analytico-functional group for silver

\section{STUDIES ON WELL-KNOWN REAGENTS}

Several well-known chelating reagents have been studied to extend their application, to improve their conditions of use or to explain unusual behaviour. The reagent phenylthiohydantoic acid has been known as a selective reagent for cobalt since 1905 . The composition of the metal complex is not sufficiently reproducible to allow it to be weighed directly, and ignition to the metal oxide is necessary. But for this drawback phenylthiohydantoic acid might well have become the preferred reagent for cobalt. Studies of this compound revealed that it is not phenylthiohydantoic acid, but carbaminothioglycollic acid anilide ${ }^{34}$ (Figure 10). The precipitate formed is tris(thioglycollic acid anilido)cobalt(III), formed by hydrolysis of the carbamino compound. It is one of the earliest examples of PFHS, although it was not recognized as such by previous investigators. Although the new conversion factor is more favourable, coprecipitation effects prevent the precipitate being weighed directly.

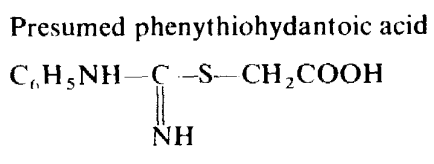

is actually

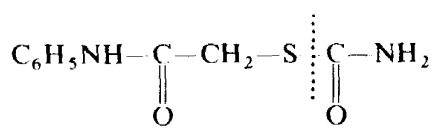

Carbaminothioglycollic acid anilide

Figure 10

Quercetin has been used as a reagent for several metals. As part of the study of the analytical chemistry of zirconium and hafnium it was found that in a $9 \mathrm{M}$ perchloric acid medium only hafnium gave a fluorescence. It was possible to determine 1-20 $\mu \mathrm{g}$ of hafnium in the presence of $100 \mu \mathrm{g}$ of zirconium. This is the first direct reaction so far reported for the determination of hafnium ${ }^{35,36}$.

Another metal pair which provides analytical problems, owing to similar chemical behaviour, is niobium and tantalum. The reagent 4-(2-pyridylazo)resorcinol (PAR), which forms coloured complexes with several metals, was found to react selectively with niobium in a tartrate-buffered medium at pH 5.8. Tantalum forms only a weakly coloured complex and the colour 
can be suppressed by the addition of more tartrate. Niobium can be determined at the $0.1 \mathrm{ppm}$ level and, in the presence of EDTA and cyanide the reaction is highly selective ${ }^{37,38}$.

Bromopyrogallol Red was also found to be a selective and highly sensitive reagent for niobium ${ }^{39}$. Under the most favourable conditions the molar absorptivity is 60000 , which is reduced to 53000 in the presence of masking agents. This is probably the most sensitive visible-range spectrophotometric method for niobium so far described.

One of the most valuable organic reagents of recent times is $\mathrm{N}$-benzoyl$N$-phenylhydroxylamine (BPHA) introduced by Shome. A comprehensive monograph on its analytical properties has been published recently ${ }^{40}$. It is used generally as a substitute for cupferron, but it is far superior. In order to improve the general precipitation process, the acetate (BPHAA) was prepared. When hydrolysed, the metal complexes were precipitated by PFHS. The separations were much better and the physical characteristics of the precipitates were improved ${ }^{41}$.

Studies on the fluorescent properties of rare earth chelates showed that 2-thenoyltrifluoroacetate was a selective and highly sensitive reagent for europium in dimethylformamide solution ${ }^{42}$. This was the first time that we found fluorine substitution to produce a superior reagent.

\section{GAS CHROMATOGRAPHY OF METAL CHELATES}

Some years ago, gas-liquid chromatographic studies of metal-chelate compounds were started by several groups of investigators. This work has restimulated interest in the properties of the classical chelate compounds, the $\beta$-diketonates. This led us to study the volatility and thermal stability of the alkali metal compounds of highly fluorinated $\beta$-diketones. Amongst these 1-(undecafluorobicyclo[2.2.1] heptan-1-yl)-4,4,4-trifluorobutan-2,4dione (Figure II) was prepared. The sodium $\beta$-ketoenolate of this is readily

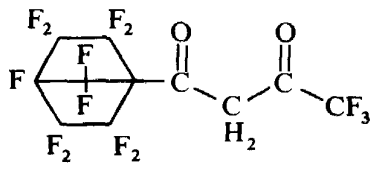

Figure 11. 1-(undecafluorobicyclo(2.2.1)heptan-1-yl)-4,4,4-trifluorobutan-2,3-dione

sublimed and is extracted from aqueous solution with diethyl ether ${ }^{43}$. Extensive studies have been made of the chelates of the series of $\beta$-diketones, listed in Table 2.

Table 2

\begin{tabular}{lll}
$\mathrm{CH}_{3} \mathrm{CCOCH}_{2} \mathrm{COCF}_{3}$ & Trifluoroacetylacetone & (TFA) \\
$\left(\mathrm{CH}_{3}\right)_{3} \mathrm{CCOCH}_{2} \mathrm{COCH}_{3}$ & Acetylpivalylmethane & (APM) \\
$\left.\left(\mathrm{CH}_{3}\right)_{3} \mathrm{CCOCH}_{2} \mathrm{COC}_{3} \mathrm{CH}_{3}\right)_{3}$ & Dipivalylmethane & (DPM) \\
$\left(\mathrm{CH}_{3}\right)_{3} \mathrm{CCOCH}_{2} \mathrm{COCF}_{3}$ & Trifluoroacetylpivalylmethane & (TPM) \\
$\left(\mathrm{CH}_{3}\right)_{3} \mathrm{CCOCH}_{2} \mathrm{COC}_{2} \mathrm{~F}_{5}$ & Pentafluoropropionylpivalylmet hane & (PPM) \\
$\left(\mathrm{CH}_{3}\right)_{3} \mathrm{CCOCH}_{2} \mathrm{COC}_{3} \mathrm{~F}_{7}$ & Heptafluorobutyrylpivalylmethane & (HPM) \\
\hline
\end{tabular}


In these ligands, the effect of the bulky t-butyl group (the pivalyl group) is modified by the alkyl group at the other end of the molecule. The fluorinated compounds are of particular interest in that the resultant chelates are appreciably more volatile than the unfluorinated compounds.

Studies of the alkali metal complexes of TPM, PPM and HPM have shown that the lithium, sodium and potassium complexes can be chromatographed separately on a silicone gum column at a temperature of $200^{\circ} \mathrm{C}$ and the retention times of the complexes are quite different ${ }^{44}$. However, when mixtures of the complexes are chromatographed, exchange reactions apparently occur at the operating temperature and the individual peaks cannot be resolved. This is a major problem with complexes of this type and it would seem to indicate that a new approach is necessary for the chromatography of the alkali metals. Considerable difficulties have also been encountered in the gas chromatography of the lead chelates of TPM, PPM and $\mathrm{HPM}^{45}$.

Some interesting new tetrakis chelates of the alkali metals and the rare earths were discovered. They can be sublimed unchanged, and chromatographed separately. However, when mixtures are chromatographed, the individual peaks cannot be resolved, probably because of exchange reactions which occur at the temperature of operation ${ }^{46}$.

Studies of monothio- $\beta$-diketones ${ }^{47,48}$ and their trifluoro-derivatives ${ }^{49}$ show that these are suitable ligands for the possible separation of various metals. Nickel, cobalt, zinc, cadmium and palladium form readily volatile bis-monothio-trifluoroacetylacetonates.

Amongst some of the new ligands which we are preparing are the so-called $\beta$-ketoamines in which the enol function of the $\beta$-ketoenol is replaced by an amine or substituted amino group. Thus acetylacetone forms with ammonia :

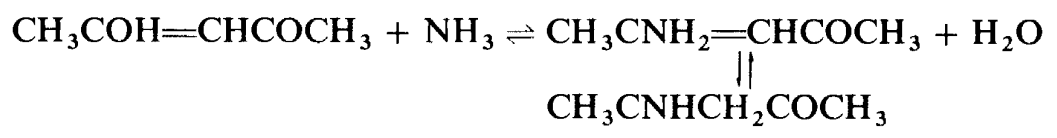

2-iminopentane-4-one

If bulky secondary amines are used in place of ammonia this offers an additional means of steric influence on subsequent chelating reactions. Studies are now in progress of the properties of new ligands such as these $e^{50}$.

Japanese investigators have been prominent in these studies on the gasliquid chromatography of inorganic systems ${ }^{51}$ and some particularly interesting results were obtained by Miyazaki and his colleagues who were the first to use derivatives of this type. A separation of nickel and copper ${ }^{51}$ as their 4-imino-2-pentanone chelates was achieved.

When acetylacetone is treated with ethylenediamine the bridged compound ethylenediiminebisacetylacetone is formed.

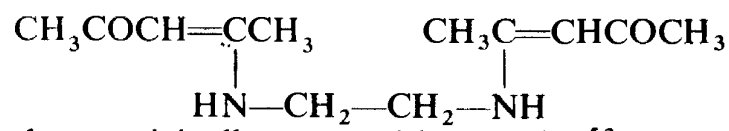

This compound was originally prepared by $\mathrm{Combes}^{52}$, but was shown by Morgan and Main-Smith ${ }^{53,54}$, in communications from this Department, 
to be a quadridentate ligand, which readily chelated with the divalent metals, nickel(II), copper(II), cobalt(II) and palladium(II).

The thermal stability and volatility of the metal complexes with these ligands has been studied, particularly those of nickel(II), palladium(II) and platinum(II). They appear to hold great promise for analytical application and the chelates of these three metals have been separated for the first time ${ }^{55}$. Our separation of these platinum metals appears to have been overlooked by later investigators, for in a recent paper published more than a year later, it is claimed that this same separation has been made for the first time ${ }^{56}$.

This type of ligand should prove a useful alternative to the monothio- $\beta$ diketones for the chromatography of the divalent transition metals. New bridged quadridentate ligands of this type are now being synthesized.

Separations on the preparative scale of aluminium, chromium and iron have been achieved using the complexes of trifluoroacetylpivalylmethane; samples of the order of $100 \mathrm{mg}$ were separated ${ }^{57}$.

A highly selective and sensitive g.l.c. method for the determination of nickel has been developed with monothiotrifluoroacetylacetonate as ligand ${ }^{58,59}$. The method has a sensitivity of $0.001 \mathrm{ppm}$ and it has been applied to the determination of nickel in oils, margarine and tea ${ }^{59,60}$. The method is simple and rapid in operation. The possibility of determining other divalent metals, such as lead. cadmium, etc. is now being studied ${ }^{60}$.

\section{MASS SPECTROMETRY OF METAL CHELATES}

The vapour pressure and thermal stability of many metal chelates are both sufficiently high to permit their direct evaporation into the ion source of a mass spectrometer and the recording of their mass spectra ${ }^{61}$. At temperatures between 100 and $500^{\circ} \mathrm{C}$ not only the metal derivatives of $1,3-$ diketones and ketoesters, but also those of 8-hydroxyquinoline ${ }^{62}$, dimethylglyoxime ${ }^{63}$ and $o$-phenanthroline have also given reproducible mass spectra. Although there is some evidence that the dissociation pattern has a temperature coefficient ${ }^{64}$, that substantial rearrangement can take place after electron impact, and that metal chelates take part in association ${ }^{65}$ and exchange ${ }^{66}$ reactions, there is a quantitative relationship between the amount of metal chelate evaporated and the integral of the ion current at any selected mass value $^{67}$. The mass value most frequently chosen is that corresponding to the molecule ion of the metal chelate. Amounts of metal chelates down to a few picogrammes may be determined, and in favourable circumstances the limit of detection is of the order of $10^{-14} \mathrm{~g}$. Most metal derivatives of 8-hydroxyquinoline evaporate without decomposition, although there is a considerable difference in their sublimation temperatures. The most volatile chelates are those of fluorinated diketones and ketoesters. Even the alkali metal $^{68}$ derivatives of these chelating agents may be determined, as well as the rare earths ${ }^{69}$, the transition and the alkaline earth metals. Because the detection depends only upon the mass of the ion, mixtures of several metals may be determined even though these have closely similar chemical properties. Thus mixtures of titanium, zirconium and hafnium have been analysed in the form of their benzoyl trifluoroacetonates ${ }^{70}$. While when small samples of metal chelates are being evaporated, the curve of the selected ion current 


\section{R. BELCHER}

with time has a Gaussian profile, the existence of isomers is sometimes revealed by the appearance of multiple maxima. In this way the cis-trans isomerism of di- and tri-valent 8 -hydroxyquinolinates ${ }^{71}$ and of the trivalent metal derivatives of asymmetrical diketones has been demonstrated ${ }^{69}$.

\section{ACKNOWLEDGEMENTS}

My thanks are due to the J. T. Baker Chemical Co. (Dr. A. J. Barnard Jr.) for giving me permission to reproduce Figures 3 and 4, which appeared originally on the front cover of the Chemist-Analyst.

\section{REFERENCES}

1 G. T. Morgan and H. D. V. Drew, J. Chem. Soc., 117, 1456 (1920).

2 C. S. Plinius, Naturilis historiae libri, XXIV, 26; Pliny’s Natural History, Vol. IX, p. $210-211$, Loeb Classical Library, London (1952).

3 M. Ilinski and G, von Knorre, Ber., 18, 699 (1885).

4 F. Welcher, Organic Analytical Reagents, Vol. II, p. 118, Van Nostrand (1947).

5 H. J. Emeleus and J. S. Anderson, Modern Aspects of Inorganic Chemistry, p. 104 et seq. Routledge (1938).

6 R. Belcher, A. Sykes and J. C. Tatlow, Anal. Chim. Acta. 10, 34 (1954).

? R. Belcher, A. Sykes and J. C. Tatlow, J. Chem. Soc., 4159 (1954).

8 R. Belcher, A. Sykes and J. C. Tatlow, J. Chem. Soc., 2393 (1957).

9 R. Belcher, M. Stacey, A. Sykes and J. C. Tatlow, J. Chem. Soc., 3846 (1954).

10 R. Belcher, A. Sykes and J. C. Tatlow, J. Chem. Soc., 376 (1955).

11 J. Hobson, Birmingham University, unpublished work.

12 W. 1. Stephen and S. Thompson, unpublished work. Abstracted, 20th IUPAC Congress, Moscow, July (1965).

13 R. Belcher, R. A. Close and T. S. West, Chemist-Analyst, 46, 86 (1957).

14 R. Belcher, R. A. Close and T. S. West, Chemist-Analyst, 47, 2 (1958).

15 R. Belcher, R. A. Close and T. S. West, Talanta, 1, 238 (1958).

16 R. Belcher, R. A. Close and T. S. West, Chem. and Ind., 1647 (1957).

17 R. Belcher, W. Hoyle and T. S. West, J. Chem. Soc., 2743 (1958).

18 R. Belcher, W. Hoyle and T. S. West, J. Chem. Soc., 133, 667 (1961).

19 R. Belcher, W. Hoyle and T. S. West, Talanta, 3, 201 (1959).

20 R. Belcher, M. A. Leonard and T. S. West, J. Chem. Soc., 2390 (1958).

21 R. Belcher. M. A. Leonard and T. S. West. Talanta, 2. 92 (1959).

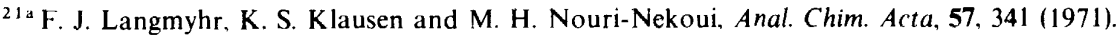

22 R. Belcher, D. I. Rees and W. I. Stephen, Talanta, 4, 78 (1960).

23 D. I. Rees and W. I. Stephen, J. Chem. Soc., 5101 (1961).

24 G. F. Kirkbright, D. I. Rees and W. I. Stephen, Anal. Chim. Acta, 27, 558 (1962).

25 M. A. Salam-Khan, E. F. Mooney and W. I. Stephen, Anal. Chim. Acta, 43, 153 (1968).

26 M. A. Salam-Khan and W. I. Stephen, Anal. Chim. Acta, 49, 255 (1970).

27 A. M. Lukin, K. A. Smirnova and N. S. Sysoev, USSR Patent 110, 966, March 3rd (1957); Chem. Abstr., 52, 13456 (1958).

28 R. A. Close and T. S. West, Talanta, 5, 221 (1960).

29 A. E. Mendes-Bezerra and W. I. Stephen, Analyst, 94. 99 (1969).

${ }^{30}$ W. I. Stephen and P. C. Uden, Anal. Chim. Acta, 39, 357 (1967).

31 W. I. Stephen. Talanta, 16, 939 (1969).

32 W. I. Stephen and A. Townshend, J. Chem. Soc., 3738 (1965).

33 W. I. Stephen and A. Townshend, Anal. Chim. Acta, 33. 257 (1965).

34 A. Bashar and A. Townshend, Analyst, 93, 125 (1968).

35 A. Brookes and A. Townshend, Chem. Commun. 24, 1660 (1968).

36 A. Brookes and A. Townshend, Analyst, 95, 781 (1970).

37 R. Belcher, A. M. Cabrera and T. S. West, Anales Real Soc. Espan. Fis. Quim. 281, 4 (1963).

38 R. Belcher, T. V. Ramakrishna and T. S. West, Talanta, 10, 1013 (1963). 
${ }^{39}$ R. Belcher, T. V. Ramakrishna and T. S. West, Talanta, 12, 681 (1965).

40 A. K. Majumdar, N-Benzoylphenylhydroxylamine and its Analogues, Pergamon Press (1972).

41 P. R. Ellefsen, L. Gordon, R. Belcher and W. G. Jackson, Talanta, 10, 701 (1963).

42 R. Belcher, R. Perry and W. I. Stephen, Analyst, 94, 26 (1969).

43 R. Belcher, A. W. L. Dudeney and W. I. Stephen, J. Inorg. Nucl. Chem., 31, 625 (1969).

44 R. Belcher, J. R. Majer, R. Perry and W. I. Stephen, Anal. Chim. Acta, 45, 305 (1969).

45 R. Belcher, J. R. Majer, W. I. Stephen, I. J. Thomson and P. C. Uden, Anal. Chim. Acta, 50, 423 (1970).

46 R. Belcher, J. Majer, R. Perry and W. I. Stephen, J. Inorg. Nucl. Chem., 31, 471 (1969).

47 W. I. Stephen, I. J. Thomson and P. C. Uden, Chem. Commun., 269 (1969).

${ }^{48}$ R. Belcher, W. I. Stephen, I. J. Thomson and P. C. Uden, J. Inorg. Nucl. Chem., 33, 1851 (1971).

49 R. Belcher, W. I. Stephen, I. J. Thomson and P. C. Uden, Chem. Commun., 1019 (1970).

50 R. J. Martin, Ph.D. Thesis, University of Birmingham (1971).

51 M. Miyazaki, T. Imanary, T. Kunugi and Z. Tamura, Chem. Pharm. Bull. (Tokyo), 14, 117 (1966).

52 A. Combes, Compt. Rend., 108, 1252 (1889).

53 G. T. Morgan and J. D. Main-Smith, J. Chem. Soc., 2030 (1925).

${ }^{54}$ G. T. Morgan and J. D. Main-Smith, J. Chem. Soc., 912 (1926).

55 R. Belcher, M. Pravica, W. I. Stephen and P. C. Uden, Chem. Commun., 41 (1971).

56 E. Bayer, H. Müller and R. E. Sievers, Anal. Chem., 43, 2012 (1971).

${ }^{57}$ R. Belcher, C. R. Jenkins, W. I. Stephen and P. C. Uden, Talanta, 17, 455 (1970).

58 R. Barratt, R. Belcher, W. I. Stephen and P. C. Uden, Anal. Chim. Acta, 58, 107 (1971).

59 R. Barratt, R. Belcher, W. I. Stephen and P. C. Uden, Anal. Chim. Acta, 59, 59 (1972).

${ }^{60}$ R. Belcher and W. I. Stephen, unpublished work.

61 A. E. Jenkins and J. R. Majer, Mass Spectrometry, p. 253, Butterworths, London (1968).

62 A. E. Jenkins, J. R. Majer and M. J. A. Reade, Talanta, 14, 1213 (1967).

63 A. E. Jenkins and J. R. Majer, Talanta, 14, 777 (1967).

${ }^{64}$ M. J. Frazer, J. R. Majer, W. E. Newton and B. Rimmer, Chem. Commun., 21, 1336 (1968).

65 J. R. Majer and R. Perry, Chem. Commun., 271 (1969).

66 J. R. Majer and R. Perry, Chem. Commun., 454 (1969).

67 J. R. Majer, M. J. A. Reade and W. I. Stephen, Talanta, 15, 373 (1968).

${ }^{68}$ R. Belcher, J. R. Majer, R. Perry and W. I. Stephen, Anal. Chim. Acta, 45, 305 (1969).

69 R. Belcher, J. R. Majer, R. Perry and W. I. Stephen, Anal. Chim. Acta, 43, 451 (1968).

70 M. G. Allcock, R. Belcher, J. R. Majer and R. Perry, Anal. Chem., 42, 776 (1970).

71 J. R. Majer and M. J. A. Reade, Chem, Commun., 58 (1970). 